\title{
Creative Therapy
}

THE history of Creative Therapy in 1 mental illness is a remarkably chequered one. Painting, drama, music, sculpture, handicrafts, dancing, even work have all been used, and used with success: but curiously the story of each is practically the samea series of spasmodic activities generally sponsored by some rather eccentric enthusiasts, who achieve excellent results for a time, but then fade away and allow what they know to be lost-until a new group arises to rediscover it in a decade or two. This is all the more surprising when we reflect how much the mood of each one of us can be affected by creative outlets, how evident it is that many artists use their media to resolve, or try to resolve their psychological problems, and how many patients tend to express themselves in many ways that are not verbal.

Even rarer are the attempts to set down systematically what has been gained by experience and to work out the basic principles on which success depends. We therefore welcome the contributors to this issue who have tried to do so. No doubt they find this easier now that such therapy has spread at last into many mental hospitals - though in Britain it is less advanced than in the U.S.A. Art

therapists exist and are in some $c^{2}$ actually on the established staff of hospital; but there are still $\mathrm{m}^{2}$ hospitals where even the idea of the could scarcely be mentioned.

What is the relation of creati therapy to occupational therapy? $D$ the latter obviate the need for former? These are questions wh need answering, for occupatiol therapy has become well establish Mr. Adamson has his answer: occll? tional therapy distracts or abs 0 while art therapy is "the use of fine arts . . . as a dynamic and uni aid to the mental patient's recover? Yet many occupational therap would hold that their work was more than a distraction absorption: and that even w they did not use the fine ar and they sometimes do-they using a dynamic aid to the patie recovery. What begins as a disth tion ends up as a form of expression for the patient.

It would thus be a pity occupational therapists or therapists to regard each other suspicion. They have a great deal common in their methods principles and are allies not riva and so of course should psychiatrists be to both of them.

\section{The Ten-Year Plan}

MOST readers will, by now, have 1 made themselves familiar with the Minister of Health's Plans for developing the health and welfare services over the next ten years as outlined in the Blue Book* presented to Parliament. Mr. Powell himself spoke about it at length at the Association of Municipal Corporations' Conference in Morecambe on April 13th.

*"Health and Welfare: The Development of Community Care"; Cmnd. 1973 H.M.S.O. 24s.
No doubt there will be criticis especially of the schemes based statistical predictions, but these sho not blind anyone to the fact that is a most progressive and flexible $\mathrm{p}$. Consultations are to continue as programme develops, and there set a real hope that the communicat will be good enough for authorities learn not only from their own mista and difficulties but from each other It is expected that many plans 
